\title{
Preparing a Generation of Lifelong Learners
}

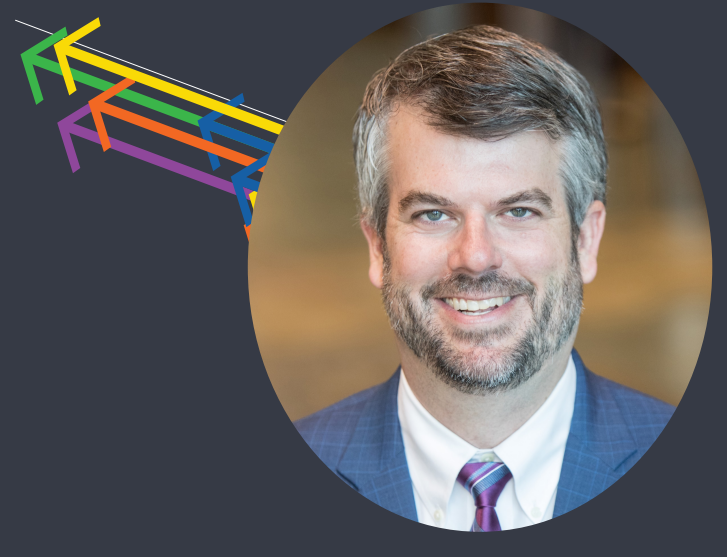

\author{
Andy Bell \\ Director of Innovation \\ National Instruments
}




\section{Era of Great Technology Acceleration}

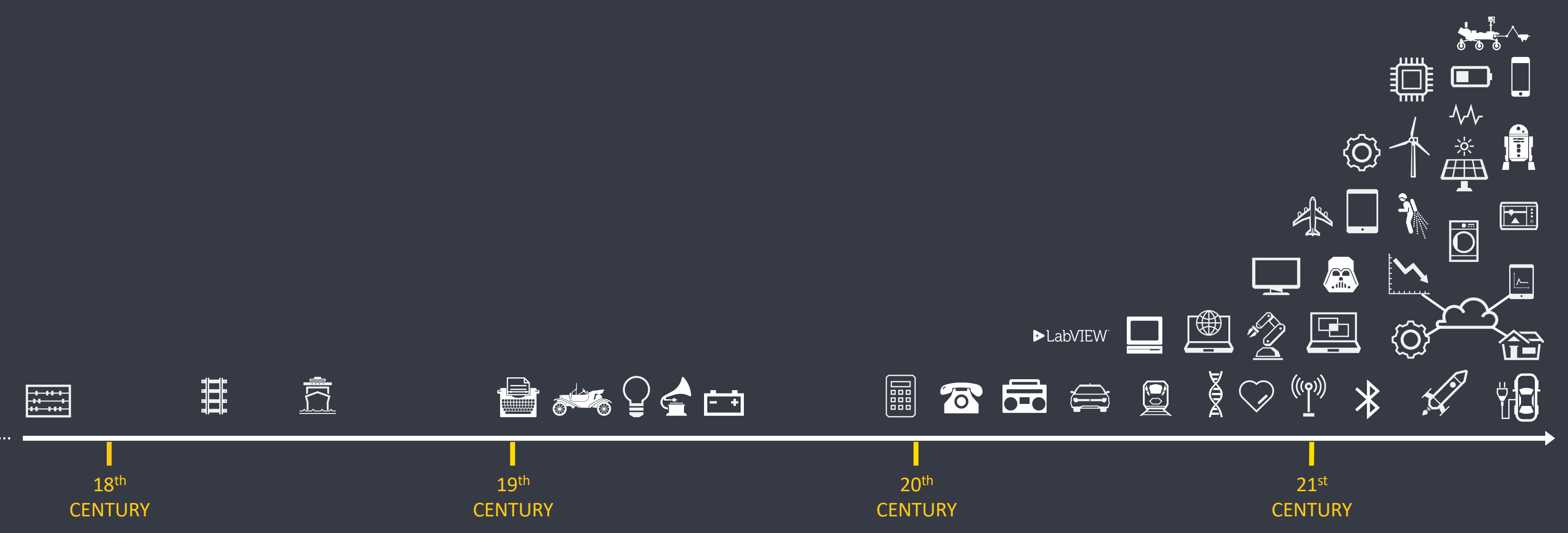




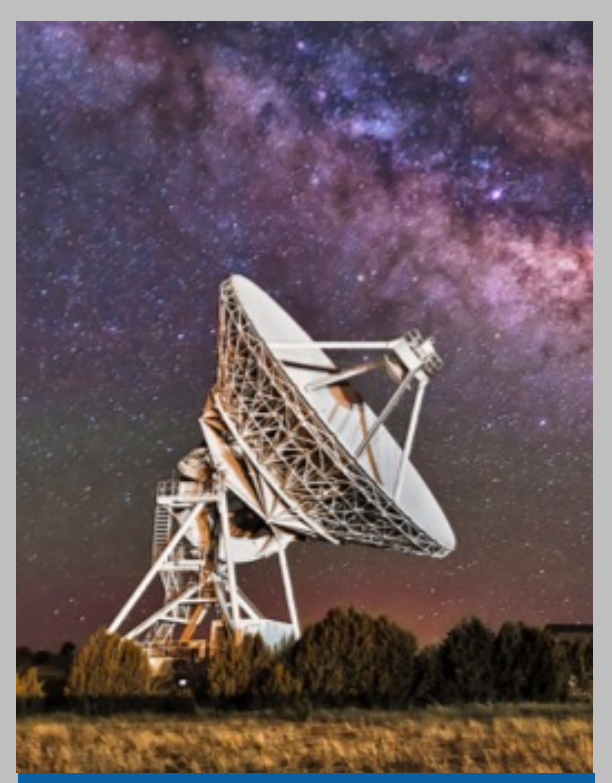

Big Physics
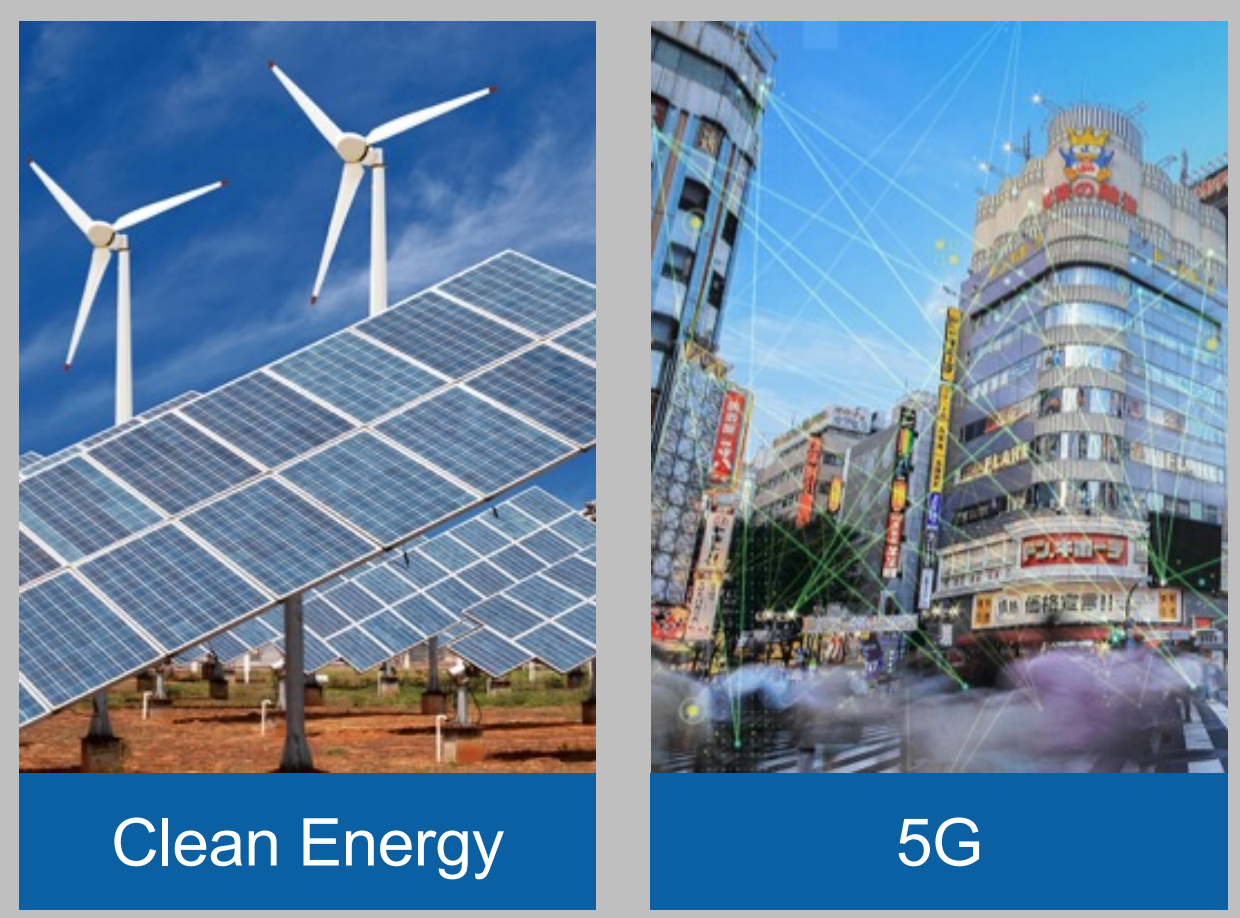

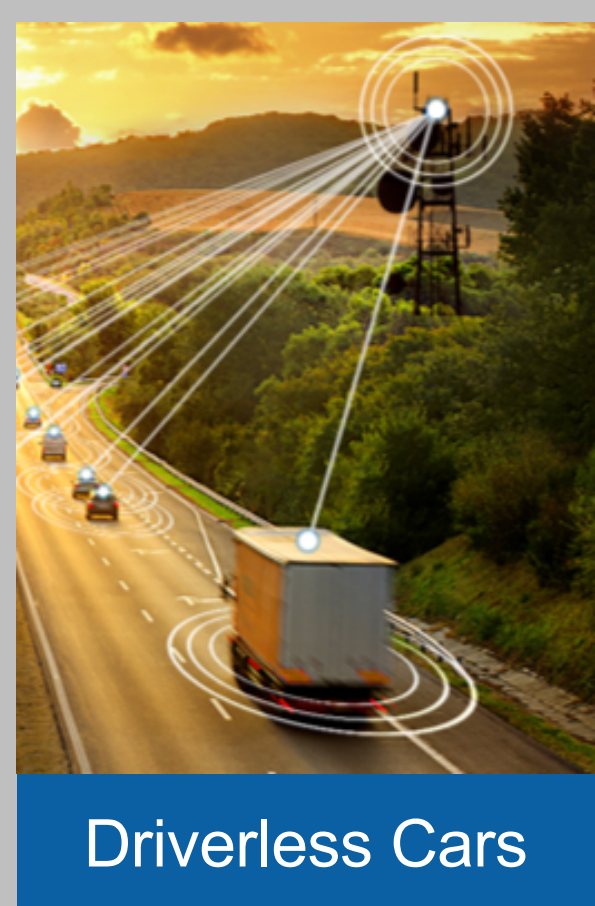




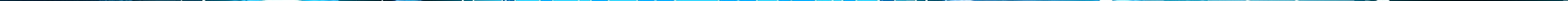




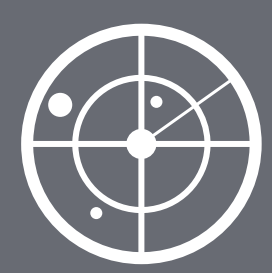

Sensing Technology

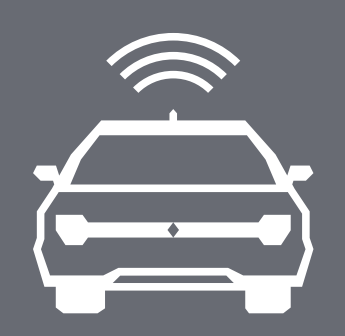

Communications Standards

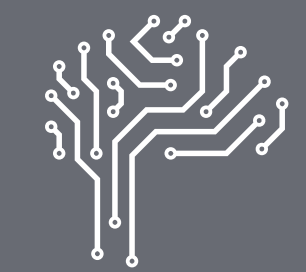

Artificial Intelligence

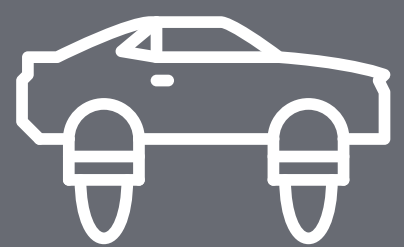

Advanced

Control Systems

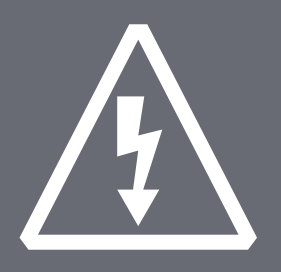

Power

Electronics 


\section{Engineering System Design}

\section{Autonomous Vehicle}

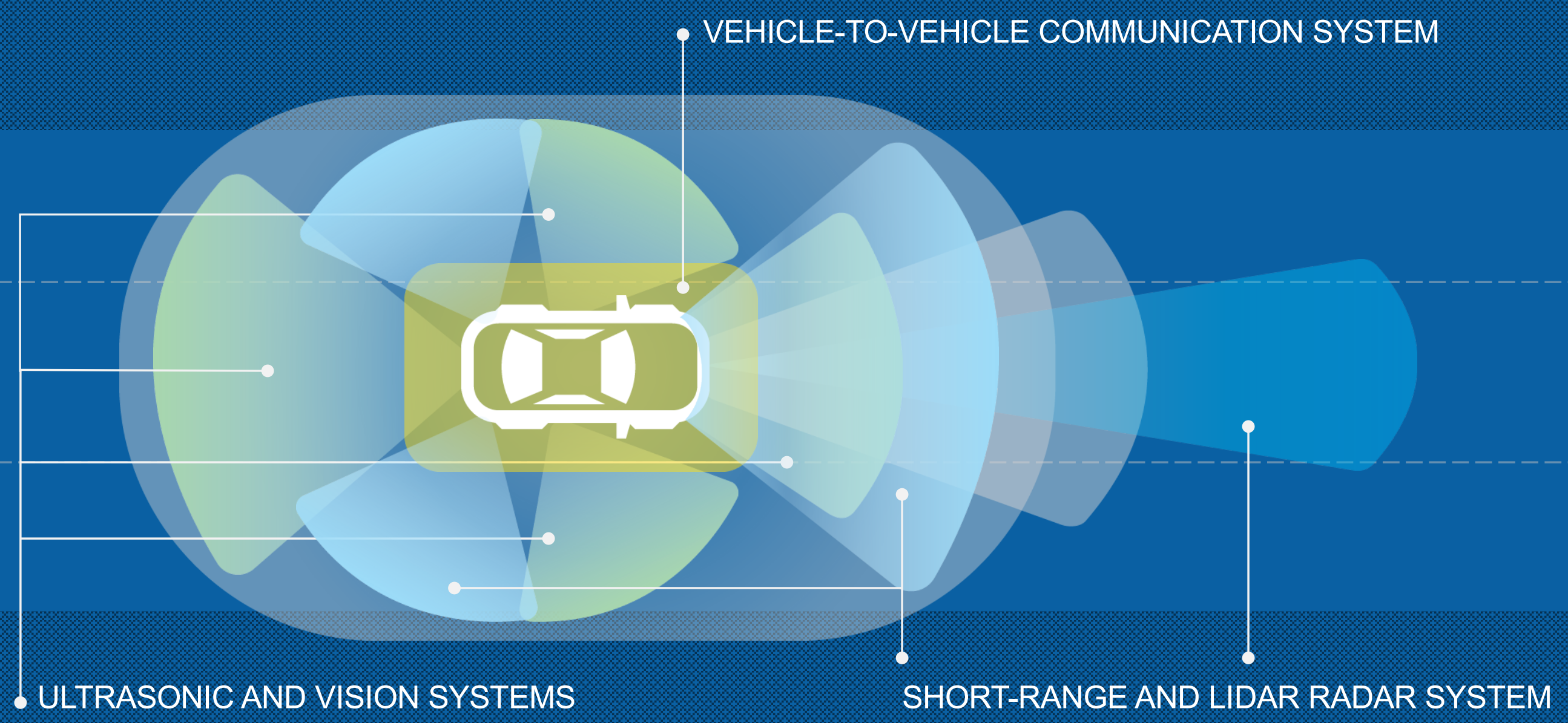




\section{Engineering Education Paradigms}

\section{National Academy of Sciences}

\section{Engineering Practice}

design according to codes and well-defined

procedures; limited use of mathematics;

many faculty with industrial experience and/or

strong ties with industry

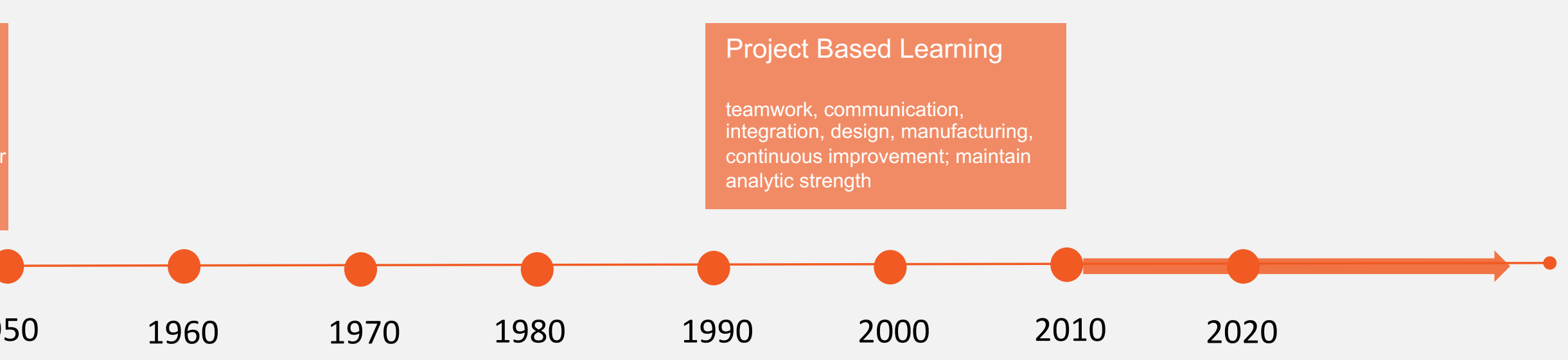




\section{Engineering System Design}

\section{Evolving the Paradigm Shift to Change Engineering Education}

\section{Engineering Practice}

design according to codes and well-defined procedures; limited use of mathematics;

many faculty with industrial experience and/or

strong ties with industry
Project Based Learning

teamwork, communication,

integration, design, manufacturing

continuous improvement; maintain

analytic strength

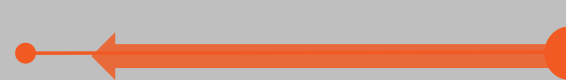

1950

1960

1970

1980

1990

2000

2010

2020

Engineering Science

fundamental understanding of phenomena; analysis; majority of faculty trained for academic research

Active Learning of Engineering Systems

experiential hands-on activities, teamwork,

communication, design, creativity and innovation, project management, ethical reasoning, leadership, global contextual analysis. Incentivize instructional faculty. Encourage improvement in pedagogy and research into learning. 


\section{Skills that Companies Need for Graduating Students}

- Good Communication Skills

- Understanding of Engineering Fundamentals

- Ability to Problem Solve

- Critical Thinking

- $\quad$ Ability to Prioritize

- Teamwork Skills \& Ability to Function in Multidisciplinary Teams

- Ability to Apply Engineering Knowledge

- Data Interpretation and Visualization

- Leadership
- $\quad$ Creativity

- $\quad$ Systems Thinking

- $\quad$ Flexibility and Ability to Adapt

- Innovation

- Understanding of Design

- Ability to Deal with Complex Problems 


\section{Teach Students to Innovate}

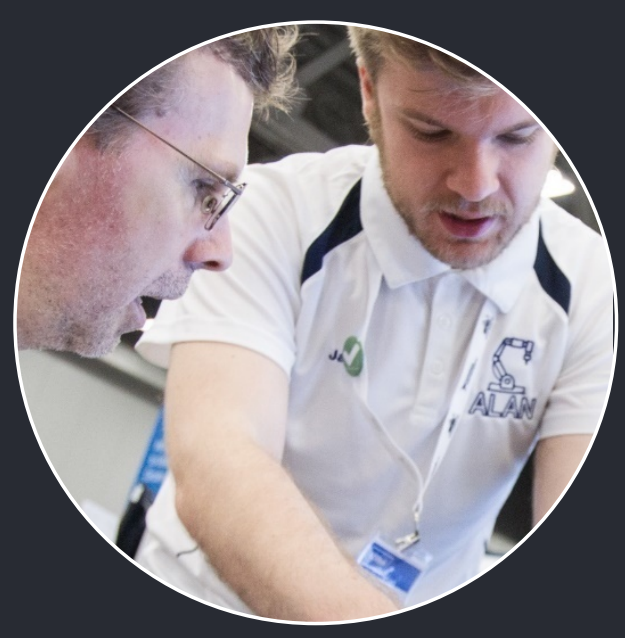

Students need to learn teamwork while solving complex, multidisciplinary problems

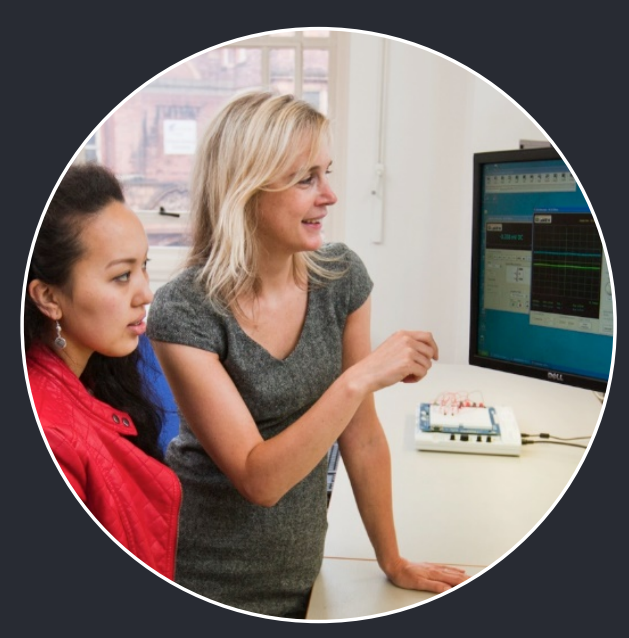

Engage and retain students by building experiences with real engineering design problems.

Educating the Engineer of 2020 National Academy of Engineering

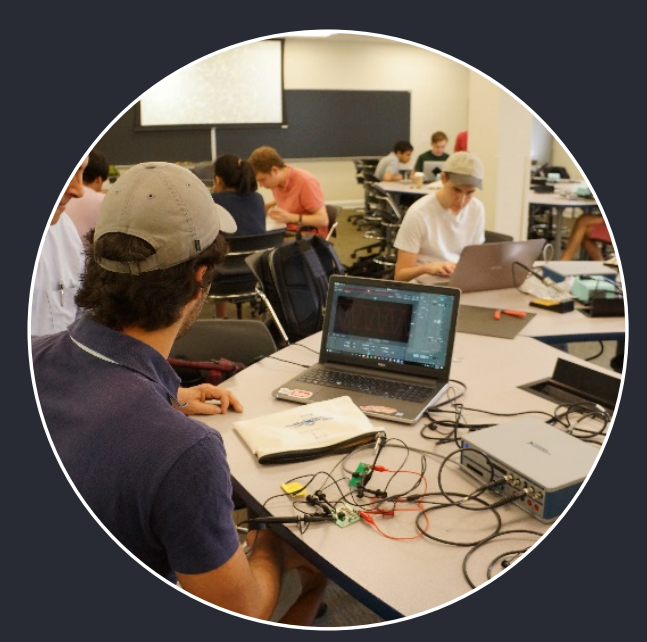

Students must work on multidisciplinary teams using modern engineering tools

Criteria for Accrediting Engineering Programs Washington Accord (of Accreditation) 
Build a Systems Approach

into Foundational Areas

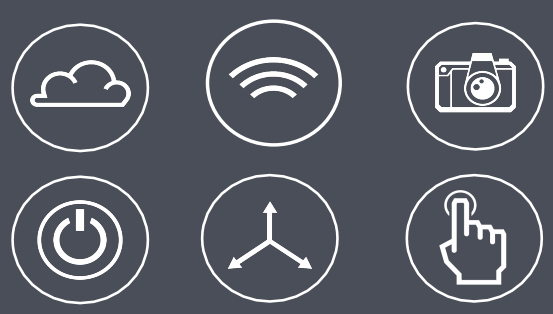

Adapt Teaching Approach to the Generation

Drive Innovation with Interdisciplinary Teamwork

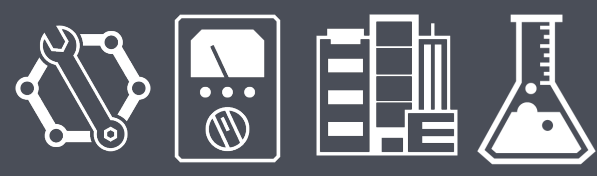

Build Academic and Industry Partners with Impactful Stakeholders

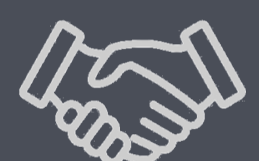

Focus on PBL to Meet

Educational \& Industry

Ready Outcomes

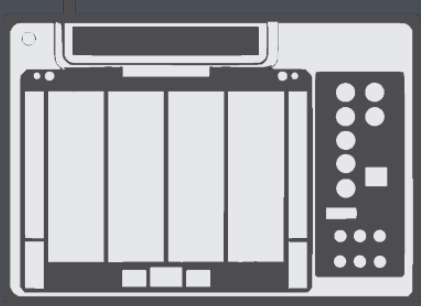

